\title{
What is a clinical academic? Qualitative interviews with healthcare managers, research-active nurses and other research-active healthcare professionals outside medicine
}

Short running title

What is a clinical academic?

\section{Authors}

Dr Lisa Newington 1,2,3

ORCID iD: 0000-0001-6954-2981

Twitter: @Lisa_Newington

Email: I.newington@imperial.ac.uk

Dr Caroline M Alexander 1,2

ORCID iD: 0000-0003-1816-8939

Twitter: @CMarthaAlex

Email: caroline.alexander1@nhs.net

Prof Mary Wells 1,3

ORCID iD: 0000-0001-5789-2773

Twitter: @elenamarywells

Email: mary.wells5@nhs.net

\section{Affiliations}

1. Department of Surgery and Cancer, Faculty of Medicine, Imperial College London, London, UK

2. Therapies Department, Imperial College Healthcare NHS Trust, London, UK

3. Nursing Directorate, Imperial College Healthcare NHS Trust, London, UK

\section{Corresponding author}

Lisa Newington

Postal address: Nursing Directorate, Education Centre ( $3^{\text {rd }}$ Floor), Imperial College Healthcare NHS Trust, Fulham Palace Road, London, W6 8RF, UK

Phone: +44 (0)20 33117422 | Email: I.newington@imperial.ac.uk 
Newington L, Alexander CM, Wells M. What is a clinical academic? Journal of Clinical Nursing 2020

\section{Acknowledgements}

The authors wish to thank the managers and research-active clinicians at Imperial College Healthcare NHS Trust who gave up their time to participate this project.

\section{Conflicts of interest statement}

The authors declare no potential conflicts of interest with respect to the research, authorship and/or publication of this article.

\section{Funding}

This service evaluation was funded by the NIHR Imperial Biomedical Research Centre (BRC). The views expressed are those of the authors and not necessarily those of the NIHR or the Department of Health and Social Care.

\section{Competing interests}

The authors declare that they have no competing interests.

\section{Authors' contributions}

All authors contributed to the study conception and design. LN conducted the interviews, led the analysis and drafted the manuscript. CA and MW provided input to the analysis, agreed the final themes and contributed to the content of the manuscript. All authors have approved the final manuscript and give approval for publication 
Newington L, Alexander CM, Wells M. What is a clinical academic? Journal of Clinical Nursing 2020

\section{Abstract}

\section{Aim and objectives}

To explore the concept of 'clinical academic' from the perspectives of healthcare managers and research-active healthcare professionals outside medicine.

\section{Background}

Clinical academics are understood to be healthcare professionals who combine clinical and research responsibilities within their role. However, there is no agreed definition for this term either within or across nursing, midwifery and the other healthcare professions outside medicine.

\section{Design}

Qualitative service evaluation, reported using the COREQ checklist.

\section{Methods}

Semi-structured qualitative interviews were conducted with a purposive sample of eight healthcare managers and 12 research-active clinicians within a UK hospital group. Interviews were audio recorded, transcribed verbatim, and analysed using the Framework method.

\section{Results}

Clinical academics were described in four themes. Two themes explored the components of the role and the contribution of these individuals to their profession: combining clinical practice, research and education; and pushing boundaries. The third theme identified the clinical academic label as: $a$ title that doesn't fit. The final theme examined a characteristic mindset of research-active clinicians. There were no clear differences in the perceptions of managers and research-active clinicians.

\section{Conclusions}

Clinical academics were perceived as valuable members of their team and were able to push the boundaries to move their profession forward. Some research-active clinicians did not identify with the term 'clinical academic' and for some managers and research-active clinicians, the term was viewed as jargonistic. A clear and accepted definition would aid development of clinical academic career pathways and identities. It would also assist in evaluating the impact of these roles.

\section{Relevance to practice}

As clinical academics roles and opportunities are being developed across the professions outside medicine, it is important to have a shared common understanding of 'clinical academic' to support the creation of career pathways and curricula, and to enable the evaluation of these roles. 
Newington L, Alexander CM, Wells M. What is a clinical academic? Journal of Clinical Nursing 2020

Key words

Clinical academic, health personnel, research personnel, health services research, nursing research, allied health research

\section{Introduction}

The National Institute for Health Research (NIHR) describes a clinical academic career as a combination of clinical research and research leadership with continued clinical practice and professional development (National Institute for Health Research 2016). Within the UK, it is estimated that $\sim 5 \%$ of medical consultants are employed in clinical academic roles, in comparison to less than $0.1 \%$ for nurses, midwives and allied health professionals (NMAHPs) (Medical Research Council 2017). There is a drive to increase this proportion 10-fold by 2030 (Association of UK University Hospitals 2016), however the absence of a defined clinical academic career pathway has been identified as a potential challenge to achieving this goal (Council of Deans of Health 2018). The lack of a clearly defined career pathway also means that use of the term 'clinical academic' (and other similar descriptors) varies, and there is a desire to reach agreement both nationally and internationally on how to describe research-focused clinical roles and activity for professions outside medicine (Carrick-Sen et al. 2019).

The Council of Deans of Health have an expanded definition, which provides separate descriptions for clinical academics and clinically active health researchers. In this context, clinical academics are those who "work in higher education institutions while providing clinical expertise to health and social care services", while clinically-active health researchers are those who "work in health and social care as clinicians to improve, maintain or recover health while also researching ways of improving outcomes for patients whose care they are planning, coordinating, managing, commissioning and quality assuring in leading clinical roles" (Council of Deans of Health 2018 p. 3). A recent special edition of the International Journal of Practice-Based Learning in Health and Social Care, which focused on clinical academic roles for NMAHPs, made a slightly different distinction. The authors suggested a broad definition of clinical academics as healthcare professionals who work concurrently in clinical and academic environments, where the academic component is researchrather than education-focused (Carrick-Sen et al. 2019; Carrick-Sen \& Moore 2019). Internationally, the term clinician-scientist is also used to describe healthcare professionals with an academic component to their role; these roles are also inconsistently defined (Hill et al. 2014; Kluijtmans et al. 2017). 
Newington L, Alexander CM, Wells M. What is a clinical academic? Journal of Clinical Nursing 2020

We had the opportunity to explore individual opinions of what constitutes a clinical academic as part of a qualitative service evaluation involving managers and research-active healthcare professionals outside medicine, at a large hospital group within the UK National Health Service (NHS). The aim was to identify the key components of 'clinical academic' from the perspectives of those who had received funding to carry out research alongside their clinical practice in either full- or part-time research fellowships; and healthcare managers who had experience of supporting research-active clinicians.

\section{Methods}

\section{Study design and approvals}

This service evaluation used a qualitative semi-structured interview design following a pre-specified protocol (Newington et al. 2020). Interviews had two components: firstly, to explore the concept of what it is to be a clinical academic; and secondly, to examine broad impacts of these roles. This article reports the findings from the first component. Approval was granted by the Imperial College Healthcare NHS Trust Clinical Audit Team (reference: 418), and the findings will contribute to the evaluation and development of the local research strategy for professions outside medicine. As this study met the UK Health Research Authority criteria for service evaluation, additional NHS ethics approval was not required (Health Research Authority 2020). All participants provided written, informed consent. Additional ethical considerations included participant anonymity, confidentiality, and the researcher-participant relationship. The service evaluation team comprised three experienced qualitative researchers: two research leads within the NHS Trust (MW and CA), and an affiliated post-doctoral researcher (LN). LN had a clinical physiotherapy role within a different NHS organisation, and was not involved in the research or clinical practice of any participants. The steps taken to assure confidentiality and anonymity are discussed below. This service evaluation was reported in accordance with the Consolidated Criteria for Reporting Qualitative Research (COREQ) checklist (Tong et al. 2007; Supplementary File 1).

\section{Participants}

\section{Research-active clinicians}

Eligible individuals were healthcare professionals from any discipline outside medicine who worked within the NHS Trust and were engaged in clinical academic activity. Included healthcare disciplines were: nursing; midwifery; the allied health professions (art therapy, dietitics, drama therapy, music therapy, occupational therapy, orthoptics, operating department practitioners, osteopathy, 
Newington L, Alexander CM, Wells M. What is a clinical academic? Journal of Clinical Nursing 2020

podiatry, prosthetics and orthotics, paramedics, physiotherapy, radiography, and speech and language therapy); healthcare science; and pharmacy.

For the purposes of inclusion, clinical academic activity was defined as engagement in research alongside clinical practice (National Institute for Health Research 2016), which was supported by additional funding from clinical research organisations or charities. Both full- and part-time research fellowships were included in this definition.

\section{Managers}

Eligible individuals were those responsible for managing a team, or teams, that included healthcare professionals engaged in clinical academic activity from any of the professions listed above. This ranged from direct line managers through to higher service level managers.

\section{Recruitment}

A purposive sampling strategy was used to promote variation among the sample. Universal sampling criteria were: clinical discipline and/or specialty; NHS grade; and gender. In addition, clinical academics were sampled according to academic level (pre-doctoral, doctoral and post-doctoral) and hospital site within the Trust (four large multi-disciplinary hospitals). Two strategies were used to recruit clinicians who were engaged in research activity. Firstly, individuals were identified from an existing database of healthcare professionals at the Trust who had received external research funding. The lead author contacted these individuals by email with an invitation to participate. Secondly, to capture any individuals not listed on the database, the service evaluation was also advertised via the NHS Trust Twitter account and by a Trust email bulletin to all staff. Interested individuals were invited to contact the lead author directly. These communications included an invitation for managers. Managers were also identified using the Trust leadership directory, and from interviewees, who were asked to provide the names of key managers within their clinical area. Managers were invited to participate by email from the lead author. For all email invitations, up to one reminder email was sent in the case of non-response. All potential interviewees were provided with the participant information sheet and all interviewees provided written informed consent.

\section{Data collection}

Participant perceptions of the term 'clinical academic' were explored using semi-structured, one-toone interviews. The interview schedules (Supplementary File 2) were developed following a scoping review of the literature and through discussion with research-active clinicians. Interview questions and format were piloted and refined before use. All interviews were conducted by the lead author 
Newington L, Alexander CM, Wells M. What is a clinical academic? Journal of Clinical Nursing 2020

and were audio recorded and transcribed verbatim by an external transcription company bound by a Non-Disclosure Agreement. Transcripts were returned to participants for comment/correction where this option had been selected on their consent form. Audio recordings were deleted once the transcripts had been checked and anonymised. Anonymisation included names, clinical disciplines, locations, and other potentially identifiable characteristics. Only the lead researcher had access to the audio recordings and pre-anonymised transcripts and did not disclose participant identity.

Recruitment continued until the research team were confident that data saturation had been achieved and the purposive sampling criteria were met. A two-fold definition of data saturation was used to encompass both sampling and analytical saturation: i) the interviewer heard the same comments repeated by different interviewees, and ii) no new codes were identified during data analysis (Francis et al. 2010; Saunders et al. 2018). Data collection and the initial phases of analysis therefore occurred concurrently.

Data collection took place over February to July 2020 and involved 20 interviews. Three researchactive clinicians and two managers were interviewed face to face; six research-active clinicians and four managers were interviewed by video call; and two research-active clinicians and two managers were interview by telephone/audio call. In addition, one research-active clinician participated by providing email responses to the interview questions as it was not possible to find a convenient time to conduct the interview by phone or video call. These individuals were recruited from a total of 28 invitation emails (17 to research-active clinicians and 11 to managers). Three individuals responded to the Twitter invitation, although all had also been identified as potential participants. Mean interview duration for research-active clinicians was 57 minutes (range 45-70). This compared with a mean of 45 minutes for managers (range 27-62).

Variation was achieved for all demographic characteristics included in the sampling frame, with the exception of gender (the majority of interviewees were female), however this imbalance reflects the distribution of non-medical healthcare professionals (World Health Organization 2019). Summary demographic details are shown in Table 1. All managers were based across two or more of the four hospital sites. Research-active clinicians ranged from those who were early in their clinical career to established senior clinicians.

\section{Analysis}

Data were managed and analysed using the Framework Method (Gale et al. 2013; Ritchie \& Spencer 1994). Two transcripts were independently coded by all authors and an initial coding framework 
Newington L, Alexander CM, Wells M. What is a clinical academic? Journal of Clinical Nursing 2020

agreed. The coding framework was applied to all transcripts by the lead author using NVivo 12 (QRS International Ltd), with additional codes added and existing codes modified to incorporate newly identified items. Alterations to the coding framework were discussed among the team and were reapplied to previously coded transcripts. Analytical ideas were logged and discussed throughout the initial coding phase and were subsequently explored using the matrices function in NVivo. The coded text was summarised to create a series of framework matrices illustrating the key points for each passage of text, which could be viewed across participants and coding topics. These charted framework matrices were reviewed by all authors to illustrate both recurring and unique themes discussed by the interviewees. In addition, the preliminary themes and sub-themes were shared with all interviewees. Six research-active clinicians and three managers provided feedback, and this was incorporated into the development of the presented themes.

\section{Results}

What is a clinical academic?

Four non-hierarchical themes were developed that described different aspects of a clinical academic (Figure 1). Interviewees found it difficult to precisely define the term, and immediate responses focused on the dual elements of clinical practice and research, which were further expanded to emphasise knowledge transfer and education as a third component. These descriptions created the theme of someone who provides a combination of research, clinical practice and education. The second theme identified clinical academics as pushing boundaries to make important contributions to their profession. The third theme focused on the use of the label 'clinical academic'; for some interviewees this was a title that doesn't fit. The final theme explored the suggestion that 'clinical academic' described a specific mindset, with individuals drawn to these roles as a natural fit for their interests.

\section{A combination of research, clinical practice and education}

The universal response from both managers and research-active clinicians was that clinical academics were individuals who were involved in providing clinical care and conducting their own research. This broad definition was summarised by interviewees $R 7$ ( $R$ - research-active clinician) and $\mathrm{M} 8(\mathrm{M}$ - manager) as follows:

"Somebody who is involved in research but beyond doing other people's research. Someone who's involved in doing their own research, is research active themselves in a particular field, whatever that is. Who also maintains clinical practice... I don't think there's a limit on whether you do it one day a 
Newington L, Alexander CM, Wells M. What is a clinical academic? Journal of Clinical Nursing 2020

month, one day a week or whatever. But you just maintain that patient contact beyond your research." R7 (doctoral)

"So, well I suppose it's somebody who is research active, and then can also kind of fit within a service, working clinically, but then also bridging that gap between... pull in research, so has dedicated clinical time and also dedicated research time within that job role, ideally." M8

Despite consensus on this overarching description, interviewees held differing views on how this definition might be operationalised, including what constituted the elements of 'clinical care' and 'research'. Interviewees presented different opinions of whether the clinical aspect required a patient-facing role, or whether this included managerial or other indirect roles, such as public health and healthcare science, as discussed by R2 and R4:

"So to me I think that it's someone that's in the clinical environment so practicing in some way, that could be like I don't know, just involved. When I normally think of academics in the past, like my lecturers, they stayed at the university, I don't know how often they visited like the hospitals so for me clinical academics are a lot more intertwined into that clinical process..." R2 (pre-doctoral)

"I mean, I suppose I disagree with the views that think of clinical as hands on, bedside or consultation healthcare provision. So I do see myself as a clinical, in the sense that I input on the delivery of the NHS... but I'm not a clinical academic where I would have a rota to see my patients as a doctor. I think a lot of the narrative we've got about clinical academics comes from the really well-defined pathways of the classic physician. I'm happy that that exists, of course, but I'm anxious that it all seems to be about that kind of model." R4 (post-doctoral)

Some interviewees highlighted a distinction between 'research' and other service development activities, such as service evaluation, audit and quality improvement, with the perception that the term clinical academic only related to those engaged in specific research activities. Others indicated that they regarded all of these elements as part of the clinical academic role and as tools to facilitate change. These differing views are demonstrated by R7 and R4:

"I think there is a... obviously there's a difference. Many people don't know that there's a difference and there are people who would call themselves clinical academics who do things like audits and service evaluations." R7 (doctoral) 
Newington L, Alexander CM, Wells M. What is a clinical academic? Journal of Clinical Nursing 2020

"And of course, you know, making explicit, if you are a [clinical] academic, we have got an expectation that you engage in research and, brackets, service evaluation, quality improvement, audit, whatever you want to call it, or at least that you facilitate it. So, you know, you must facilitate that intellectual activity, either yours or others." R4 (post-doctoral)

A further description of the 'research' aspect of a clinical academic role was provided by M4, who suggested that the research activity required external funding and time built into their role for the individual to be considered as a clinical academic:

"Well anybody who has a clinical background who's doing research. Doing funded research. A bit more than an improvement project that you might get a paper [from]. I would define it -clinical academic is somebody who's got research funding and time dedicated to academic research." M4

Education was discussed as the third element of a clinical academic. There was an expectation that as well as conducting their research and clinical practice, these individuals also have the responsibility of sharing their knowledge and skills with others. This was expressed by researchactive interviewees across the clinical/research levels, and was not specifically interpreted as providing university-based education and incorporated knowledge-sharing in both clinical and academic settings, as described by R6 and R10.

"So I'd define it as somebody who has been successfully able to combine both clinical work with research work, but I guess it's broader than that too, it's someone who's very aware of encouraging others to participate in research. But I feel that there's also as part of that role a responsibility to upskill others and undertake teaching, so teaching in clinical skills but also teaching in just core research skills as well." R6 (post-doctoral)

"It means someone who can use their research expertise - methodology as well as up to date understanding of the literature - and clinical experience gained, whilst undertaking research, often roles that are not supported during a standard clinical role to enhance clinical work for the benefit of improving effective and efficient patient care as well as supporting peers and their work. It also means bringing in the clinical understanding into the teaching of research students." R10 (postdoctoral) 
Newington L, Alexander CM, Wells M. What is a clinical academic? Journal of Clinical Nursing 2020

An important aspect of the 'education' component of clinical academics was raised by several managers, who suggested that they had personally benefitted from the knowledge and expertise of the research-active clinicians within their team. This included being kept informed of the current literature and best practice, activities which they might not otherwise have time for, as illustrated by M8 and M7:

"I find it particularly useful, I mentioned before about easy access to the evidence... So you know, often that's, 'What staffing do you need, and what's the evidence for that?' I can easily just reach out to those who are on fellowships and say, 'What have you got? Have you got anything?' Or point me in the direction in terms of a quick little supporting statement or study that can help build this case, so that's really helpful as well." M8

"I really rely on [name] as our, sort of, academic person at a basic level, to be my eyes and ears of what's going on outside of [clinical department], and to be that to me. So, I very much use her skills and her interest in research to tell me what's happening out there, so I can think about how we can bring it into our service, and how we can shape our service and progress our service with her knowledge and understanding." M7

\section{Pushing boundaries}

For some interviewees, clinical academic encompassed more than research, clinical practice and education; these individuals reported that clinical academics also had the responsibility of challenging the status quo and driving their profession forward. These points are illustrated by R5 and R4 below:

"I think they should role-model and drive the agenda of the area of care that they work in forward by having depth of interest and knowledge. And, yeah, disrupt some of the more, you know, older agendas and make sure that the agenda of the clinical group they're from is represented and enriched." R5 (pre-doctoral)

"That means that people are pushing the boundaries, or they should be, which, you know, is the other aspect, what is it that we're researching and doing that is truly boundary pushing and not more of the same." R4 (post-doctoral)

Similar points were raised by several of the managerial interviewees, as reported by M7 and M5: 
Newington L, Alexander CM, Wells M. What is a clinical academic? Journal of Clinical Nursing 2020

"Because I don't have thinking room in my post, there's never thinking room in my role, and so you need these people that have got that time and space, and desire to think and to do things a bit differently." M7

"Because they're, hopefully, pushing the boundaries, and, sort of, creating new knowledge, and better ways of doing things in the sphere in which they're working." M5

These descriptions from research-active clinicians and managers all emphasise a leadership aspect to clinical academic roles. These individuals were seen as the driving-force for relevant and evidencebased changes in clinical practice, and being well placed to direct change both within their clinical teams and their professional bodies.

\section{A title that doesn't fit}

Interviewees reported that the term clinical academic was not currently used in job titles or descriptions within the hospital group, although one post-doctoral interviewee reported that the term was used to describe the collective group of research-active clinicians in some circumstances:

"I mean, none of us have been given [a clinical academic title] - although when they want to parade that we have clinical academics here, they call us that." R3 (post-doctoral)

A few research-active clinicians indicated that the term clinical academic did not apply to them or their current situation. This was despite all participants having funding to carry out research activities in addition to their usual NHS role. For some pre-doctoral interviewees (across the different clinical disciplines), there appeared to be a perception that clinical academics were those with a more senior and embedded academic career than their own, as illustrated by R11 and R2 below. This was also discussed by M7:

"[A clinical academic is] someone who's employed by the college, who may do some clinical PAs [programmed activities] but ultimately they're kind of employed by the college, measured by the college, having to submit all the things that they have to do to keep their points up and that kind of thing, which is a bit different to what I need and have to do." R11 (pre-doctoral)

"I mean I don't really consider myself an academic yet because I'm so new so I feel like I'm learning how to do that part of it so it's really hard to consider myself a clinical academic right now, it's something that I aspire to be." R2 (pre-doctoral) 
Newington L, Alexander CM, Wells M. What is a clinical academic? Journal of Clinical Nursing 2020

“Oh, I don't know. I mean, clinical academics, I think, are people that are, sort of, studying at doctorate level. That's my interpretation of it." M7

For a small minority of interviewees, the term clinical academic did not seem relevant, with one manager expressing: "No, I read it and I thought it's a bit of a meaningless term" (M3). Similarly, one pre-doctoral researcher felt the term was jargonistic, although benefits of using 'clinical academic' in their title were also noted:

"It seems like a term that was constructed in a board meeting somewhere. And it - what the actual term means for me: not much! It's useful for thinking of my own role in different scenarios, but on the whole, I'm not particularly fixed by it. I use it when writing grovelly emails to use these people's questionnaires for free! ... It does give a weight to the role which otherwise would be missing and then it elevates the position of people who aren't medics doing research, it will elevate them to parity of some degree." R12 (pre-doctoral)

There was only one suggestion of an alternative term that could be used to describe this group of individuals. A pre-doctoral interviewee mentioned that "clinical researchers as opposed to a clinical academic" better described their role (R11).

\section{A mindset}

For most research-active clinicians, the concept of 'clinical academic' appeared to resonate with their own role, even if the term did not quite capture the whole picture, and for managers it was readily applied to individuals within their team. It appeared that many interviewees were drawn to clinical academic opportunities as a vocation and a defining characteristic of their future career. This clinical academic 'mindset' was widely reported across all academic levels, as exemplified in the following quotes from R8, R1 and R3:

"To be very honest, I think, I would love to be a person [who works in research and clinical practice] because we are just in the beginning... And this is what I want to do. I want to grow professionally in this branch, and I would like to do a PhD on this particular topic." R8 (pre-doctoral)

"So, I guess the biggest impact for me is it sort of tells me what I want my career to be, from a place where, like five years ago, I didn't know. I was - I felt quite lost and actually now I feel quite sure." R1 (doctoral) 
Newington L, Alexander CM, Wells M. What is a clinical academic? Journal of Clinical Nursing 2020

"I listen to my patients and I'm often taken aback by either how they haven't improved or questioning how we might have managed them differently. So, it was really my driver to be somebody that could build the evidence that would support how we assess and treat our patients, how we measure the outcomes of that, that would improve the care that we deliver, but that also as I was doing that, I would be bringing my team and my network and my institution along with me. To me, that part of a clinical academic, it shines for me." R3 (post-doctoral)

More than half of interviewees also noted that in their experience, engaging in clinical research was perceived by some of their non-research-active colleagues as a vanity project. They did not believe that this was a fair representation of the effort involved in applying for funding and conducting a piece of research or the benefits that it brings to patients and clinical teams, as summarised by R8 and R3 below. One manager (M5) suggested that clinical academics themselves had a responsibility to counter this misperception:

"Yes, but also part of the funding - which is extremely important and I'm extremely grateful I got this opportunity. I think also the fact that your clinical team realises that something is not selfish for you. It's kind of an important... It's just your way of doing something, the same as another colleague may want to do a postgrad in [specific clinical techniques] or something else. It's not selfish." R8 (predoctoral)

"You are still clinically embedded, you're a leader in your team, you're driving forward the evidence for what you do and promoting best practice, best care for your patients, and working to have best outcomes with them. And that's always what I wanted. I never wanted to do a sort of vanity project, you know. I wanted to see what I was doing change practice with my patients and see them have better outcomes." R3 (post-doctoral)

"That person, I think, has huge responsibility because, not only are they doing this great piece of work, but they have a responsibility to advocate for that piece of work and use it as an opportunity to convert people's thinking around them. [They] need to understand the positioning, and not make any assumptions that everybody shares the same mindset as they do. And, also, be mindful that if they're leading on a piece of work, their language, and everything else, can be, again, alienating other colleagues." M5

\section{Discussion}

Clinical academic roles were broadly identified by both managers and research-active clinicians as combining three elements: clinical practice, research, and education. This borders the two separate 
Newington L, Alexander CM, Wells M. What is a clinical academic? Journal of Clinical Nursing 2020

definitions of clinical academic and clinically active health researchers used by the Council of Deans of Health (Council of Deans of Health 2018), as outlined in the introduction. This conceptualisation of the role also appears to have a greater reference to teaching and education than the definition used by Carrick-Sen et al. (2019). Interestingly, the elements reported by interviewees fit most closely with the NHS Healthcare Careers and Medical Schools Council description of clinical academic medicine as "doctors who spend part of their time treating patients in the national health service and part of their time undertaking research and educating the next generation of doctors" (Medical Schools Council 2018; NHS Health Careers 2020).

Even with a broad definition of clinical academic encompassing clinical practice, research and education, there was a lack of clarity regarding the required qualifying criteria for each of these elements. For some interviewees there appeared to be an element of protectionism, specifically surround the components of 'research', others were happy to include an array of activities, including audit and service evaluation. Varying components of clinical academic roles have also been reported in the literature. A recent systematic review of clinical academic roles within allied health (termed 'research positions within healthcare') reported little overlap across a list of 26 different job components (Wenke \& Mickan 2016). Interestingly nearly all seven of the included papers reported an education and training component, whereas only one reported clinical work.

In the current study, interviewees identified that pushing boundaries and leadership were also important features of clinical academics. Leadership components of clinical academic roles were also identified in the systematic review discussed above, including: attracting grant funding; managing events and conferences; and leading/collaborating with networks, but again there was little crossover between studies (Wenke \& Mickan 2016). Within the UK, an application was submitted to establish clinical academic apprenticeship positions at a doctoral level (Clinical Academic Professional Trailblazer Group 2018). Leadership was a strong focus of the expected occupational duties for these positions within all aspects of the role, suggesting that leadership has been identified as a key feature of clinical academics within the national conversation.

Not all research-active clinicians felt that the term 'clinical academic' reflected their role, and others saw only limited value in the term. Issues with terminology are not unique to research-active roles within healthcare and have also been discussed with regard to nurse practitioners and clinical nurse 
Newington L, Alexander CM, Wells M. What is a clinical academic? Journal of Clinical Nursing 2020

specialists (Cooper et al. 2019), and advanced clinical practitioners (Smith et al. 2015). If a shared understanding of clinical academic is to be established across national and international settings, this needs to be meaningful to clinicians and managers at all levels. Additionally, it is important that the terminology, training and qualifications required are commonly understood in an agreed framework. Our study took place in an acute healthcare organisation and it would be interesting to explore whether perceptions differ in community and public health arenas.

Several interviewees stressed their perceived distinction between clinical academics and academics (with a clinical background). The latter were associated with delivering university-based education and research, with interviewees often recalling lecturers from their own clinical training. The former were associated with delivering in-practice education and research, in addition to clinical activities. There were clear areas of overlap, but this distinction appeared important for interviewees, many of whom aspired to a clinical academic role. As there are increasing opportunities for blended roles within healthcare and higher education, these perceived distinctions are unlikely to be absolute and more than one term may be required to accommodate the different elements of 'clinical academic' that were described by interviewees.

The alignment of the views of research-active clinicians and managers was an unexpected finding. Managers in the current study were not deliberately chosen as individuals known to be proponents of clinical academic roles, nor were participants recruited as research-active clinician/manager pairs. However, managers who agreed to participate in an interview on the topic of clinical academics were likely to be somewhat engaged in this issue. Healthcare managers have been identified as having an important role in clinical academic pathways, with non-facilitating leadership at organisational and local levels seen as a key barrier in the development of clinical academic opportunities elsewhere (Richardson \& Westwood 2019; Trusson et al. 2019; van Oostveen et al. 2017). Similarly, workplace support and mentorship were found to be influential in maintaining clinical academic activity (Boyd et al. 2019; Roddam et al. 2019). In the current study, managers highlighted the personal benefits that they had experienced from having research-active clinicians on their teams. This included being kept informed of the current literature and best practice and using this to shape their service. As the narrative is often directed at a lack of managerial support for research-active clinicians, these reported positive impacts also need to be acknowledged. Managers in the current study also reported a need for research-active clinicians to do more to advertise the 
Newington L, Alexander CM, Wells M. What is a clinical academic? Journal of Clinical Nursing 2020

potential impacts of their role. A need to 'sell the benefits' of clinical academic careers has also been highlighted elsewhere (Roddam et al. 2019).

In the current study, the essence of a clinical academic appeared to exist outside the specific term or job label. Both managers and research-active clinicians described identifying a particular mindset of clinicians who were engaged with research, which focused on their approach to questioning and improving practice. It may be that identifying with the role and concept of being a clinical academic is more important than the label. The idea of developing an identity as a research-active clinician has been explored in other settings. A Dutch study of novice clinician-scientists (nurses and physiotherapists who had completed a research MSc) described them as brokers between the two different worlds of clinical care and research, with individuals primarily identifying as a clinician, and experiencing challenges in combining both elements (Kluijtmans et al. 2017). Conversely, an Australian study involving established clinician researchers described a fully integrated personal and professional identity that fused clinician-researcher (Harvey et al. 2016). In the current study, the significance of identity was illustrated by several pre-doctoral researchers, who suggested that the term clinical academic did not apply to them yet. For these individuals, the term appeared to be an aspiration for career progression and a future role. In the UK, the ICA (integrated clinical academic) programme offers fellowships at pre-doctoral, doctoral and post-doctoral levels, all titled clinical academic (Health Education England 2018). This raises the question of whether there is a wider perception that doctoral training is required before being afforded a 'clinical academic' title. None of the interviewees had a job title of clinical academic, however the value of using this title was highlighted as a means of categorising an otherwise heterogenous group of clinicians and in labelling this aspect of their role to others.

The dual identity of clinician and researcher that has been explored in existing research (Hay-Smith et al. 2016; Kluijtmans et al. 2017) may need to be further extended for clinical academics to incorporate the education and boundary-pushing elements that were also identified by interviewees. Alternatively, these elements may be perceived as intrinsic to the identities of both clinicians and researchers and not separate entities. With the development of established clinical academic roles and pathways, there is a need to further explore this issue of identity. The blending of clinician and researcher roles with education and knowledge transfer, leadership, innovation, and transformation make clinical academic roles unique. 
Newington L, Alexander CM, Wells M. What is a clinical academic? Journal of Clinical Nursing 2020

Interviewees in the current study were keen to point out that their research involvement should not be viewed as a self-serving vanity project, rather the drive was a desire to improve services for patients. That more than half of participants should mention this without prompting, suggests concerns about how these roles are perceived by others. For clinical academics across the healthcare professions to succeed, misconceptions about the drivers behind these roles must be addressed. Assessing and demonstrating the wide-ranging benefits of clinical academics themselves, as well as the implementation of their research findings into practice, might aid the acceptability and perceived value of these roles. With the growing focus on research impact rather than pure academic outputs, there is an opportunity to capture and communicate the value of clinical academics in nursing, midwifery, allied health and other healthcare professions outside medicine. Perhaps this will provide greater appreciation of both the concept and label of 'clinical academic'.

\section{Limitations}

An important limitation of the current study is that it involved individuals from a single healthcare organisation, and therefore the interviewees' experiences may differ from those in other healthcare settings either within or outside the UK. However, we believe this is a useful contribution to the discussion around clinical academic roles within healthcare professions outside medicine. The differences in opinion that were identified in the current study highlight that even within a single hospital group a shared understanding of 'clinical academic' is lacking.

The term clinical academic was chosen as the descriptor throughout. This appears to be the most commonly used term within the NHS (Association of UK University Hospitals 2016; Clinical Academic Professional Trailblazer Group 2018; Council of Deans of Health 2018; National Institute for Health Research 2016), but we appreciate that other terminology is used elsewhere, for example: clinician scientist (Kluijtmans et al. 2017), clinician researcher (Harvey et al. 2016) and research-active clinician (Siedlecki \& Albert 2016). It is not clear whether our findings also translate to these different descriptors.

We acknowledge that the research team comprised research-active clinicians whose experiences contributed to the development of the study. Steps were taken to minimise the influence of the study team on the interview process, analysis and reporting, including: a lead researcher from 
Newington L, Alexander CM, Wells M. What is a clinical academic? Journal of Clinical Nursing 2020

outside the hospital organisation; pre-piloting and refining the interview schedule with additional research-active clinicians; involvement of interviewees in the review and development of the themes and subthemes; and agreement from interviewees on the final findings.

Study participants were a self-selected population who responded to email and social media invitations. It is possible that other individuals within the organisation hold different views, particularly those without experience of clinical research. However, as the aim was to explore the concept of clinical academics, we wanted to include individuals who had some experience of this term and the associated roles. If a standardised definition is established, it would be helpful to explore what this means to clinicians who are not activity engaged in research, and to different patient groups.

It is also possible that interviewees may have responded in a way that they felt was socially desirable. Involvement of a lead researcher from outside the organisation and reassurances of confidentiality and anonymity of all data were strategies designed to give confidence to interviewees that they could speak openly.

\section{Conclusions}

Clinical academics were described as individuals who combined clinical practice, research and education. Existing definitions of clinical academic roles for healthcare professions outside medicine have placed less emphasis on the contribution these individuals make to academic and clinical education, but if this is occurring in practice, it may be an important addition in the development of clinical academic career paths and curricula. Clinical academics were perceived as valuable members of their clinical teams and were able to push the boundaries to move their profession forward in the generation and delivery of evidence-based care. It was suggested that clinical academics have a specific mindset of questioning clinical practice and exploring ways to make improvements; however, it is currently difficult to explore the impact of these roles in the absence of an agreed definition or job description. Interestingly some research-active clinicians reported that the term clinical academic did not fit with their role, and for some managers and research-active clinicians the term was viewed as jargonistic. An agreed and consistently used definition would also aid the development of a clinical academic identity and perhaps unite research-active clinicians from different disciplines. 
Newington L, Alexander CM, Wells M. What is a clinical academic? Journal of Clinical Nursing 2020

Relevance to practice

As clinical academics roles and opportunities are being developed across nursing and other professions outside medicine, it is important to establish a shared understanding of 'clinical academic'. This will support the creation of career pathways and curricula, and will enable the evaluation of these roles.

What does this paper contribute to the wider global clinical community?

- This qualitative service evaluation highlights a need to clearly define the term clinical academic, and for this to be translatable to local, national and international settings.

- Clinical academics were perceived as more than a fusion of researcher and clinician, and performed valuable roles within their clinical teams. 
Newington L, Alexander CM, Wells M. What is a clinical academic? Journal of Clinical Nursing 2020

\section{References}

Association of UK University Hospitals (2016). Transforming healthcare through clinical academic roles in nursing, midwifery and allied health professions: A practical resource for healthcare provider organisations. Available at: https://councilofdeans.org.uk/2016/11/transforminghealthcare-through-clinical-academic-roles-in-nursing-midwifery-and-allied-health-professions/ (accessed 10 October 2020).

Boyd M, Gall SB, Rothpletz-Puglia P, Parrott JS, King C, \& Byham-Gray L (2019). Characteristics and drivers of the registered dietitian nutritionist's sustained involvement in clinical research activities: A mixed methods study. Journal of the Academy of Nutrition and Dietetics, 119(12), 2099-2108.

Carrick-Sen D, \& Moore A (2019). Editorial: Improving care and outcome through NMAHP researchfocused clinical academic roles - an international perspective. International Journal of PracticeBased Learning in Health and Social Care, 7(2), ii-vi.

Carrick-Sen D, Moore A, Davidson P, Gendong H, \& Jackson D (2019). International perspectives of nurses, midwives and allied health professionals clinical academic roles: Are we at tipping point? International Journal of Practice-Based Learning in Health and Social Care, 7(2), 1-15.

Clinical Academic Professional Trailblazer Group (2018). Proposal to develop an occupational standard for an apprenticeship. Available at: https://haso.skillsforhealth.org.uk/wpcontent/uploads/2018/11/2018.11.08-Clinical-Academic-Professional-Anon-proposal.pdf (accessed 19 October 2020).

Cooper MA, McDowell J, \& Raeside L (2019). The similarities and differences between advanced nurse practitioners and clinical nurse specialists. British Journal of Nursing, 28(20), 1308-1314.

Council of Deans of Health (2018). Nursing, midwifery and allied health clinical academic careers in the UK. Available at: /councilofdeans.org.uk/wp-content/uploads/2018/08/Nursing-midwiferyand-allied-health-clinical-academic-research-careers-in-the-UK.pdf (accessed 10 December 2019).

Francis JJ, Johnston M, Robertson C, Glidewell L, Entwistle V, Eccles MP, \& Grimshaw JM (2010). What is an adequate sample size? Operationalising data saturation for theory-based interview studies. Psychology and Health, 25(10), 1229-1245.

Gale NK, Heath G, Cameron E, Rashid S, \& Redwood S (2013). Using the framework method for the analysis of qualitative data in multi-disciplinary health research. BMC Medical Research Methodology, 13, 117.

Harvey D, Plummer D, Nielsen I, Adams R, \& Pain T (2016). Becoming a clinician researcher in allied health. Australian Health Review, 40(5), 562-569.

Hay-Smith EJC, Brown M, Anderson L, \& Treharne GJ (2016). Once a clinician, always a clinician: a systematic review to develop a typology of clinician-researcher dual-role experiences in health research with patient-participants. BMC Medical Research Methodology, 16, 95.

Health Education England (2018). Clinical Academic Careers Framework: A framework for optimising clinical academic careers across healthcare professions. Available at: http://hee.nhs.uk/wpcontent/blogs.dir/321/files/2014/07/2014-12-CAC-Framework-21-1-15.pdf (accessed 10 October 2020).

Health Research Authority (2020). HRA Decision Tool. Available at: http://www.hradecisiontools.org.uk/research/ (accessed 30 November 2020). 
Newington L, Alexander CM, Wells M. What is a clinical academic? Journal of Clinical Nursing 2020

Hill NL, Yevchak A, Kolanowski AM, Penrod FJ, Milone-Nuzzo PF, Sawyer AM, Metzger B, \& Therrien $B$ (2014). What it takes: Perspectives from developing nurse scientists. Journal of Nursing Education, 53(7), 403-409.

Kluijtmans M, de Haan E, Akkerman S, \& van Tartwijk J (2017). Professional identity in clinicianscientists: brokers between care and science. Medical Education, 51(6), 645-655.

Medical Research Council (2017). UK-wide survey of clinical and health research fellowships. Available at: https://mrc.ukri.org/news/browse/survey-reveals-increases-in-early-careerclinical-and-health-research-fellowships/ (accessed 10 October 2020).

Medical Schools Council (2018). Clinical academia. Available at: https://www.medschools.ac.uk/ourwork/clinical-academia (accessed 03 April 2020).

National Institute for Health Research (2016). Building a research career: A guide for aspiring clinical academics (excluding doctors and dentists) and their managers. Available at: https://www.clahrc-eoe.nihr.ac.uk/2016/02/building-a-research-career-a-guide-for-aspiringclinical-academics-and-their-managers-from-the-nihr/ (accessed 03 April 2020).

Newington L, Alexander CM, \& Wells M (2020). Qualitative evaluation of the impact of clinical academic activity among nurses, midwives, allied health and other professionals outside medicine (protocol). Open Science Framwork (OSF). Available at: https://osf.io/p8hyd/ (accessed 21 October 2020).

NHS Health Careers (2020). Clinical academic medicine. Available at: https://www.healthcareers.nhs.uk/explore-roles/doctors/career-opportunitiesdoctors/clinical-academic-medicine (accessed 10 October 2020).

Richardson A, Avery M, \& Westwood G (2019). A cross-funder survey of enablers and barriers to progressing a research-related academic career in the non-medical health professions. Available at: https://www.hee.nhs.uk/printpdf/our-work/clinical-academic-careers/integrated-clinicalacademic-ica-programme (accessed 21 October 2020).

Ritchie J, \& Spencer L (1994). Qualitative data analysis for applied policy research. In A. Bryman \& R. Burgess (Eds.), Analysis Qualitative Data (pp. 173-194).

Roddam H, Cross L, Georgiou R, Gibson J, Jones S, Olive P, Smith G, \& Thomas L (2019). Developing clinical academic researchers: Insights from practitioners and managers in nursing, midwifery and allied health. British Journal of Health Care Management, 25(9), 282-292.

Saunders B, Sim J, Kingstone T, Baker S, Waterfield J, Bartlam B, Burroughs H, \& Jinks C (2018). Saturation in qualitative research: exploring its conceptualization and operationalization. Quality and Quantity, 52(4), 1893-1907.

Siedlecki SL \& Albert NM (2016). Research-active clinical nurses: against all odds. Journal of Clinical Nursing, 26, 766-773.

Smith T, Harris J, Woznitza N, Maresse S, \& Sale C (2015). Conceptualisation of the characteristics of advanced practitioners in the medical radiation professions. Journal of Medical Radiation Sciences, 62(3), 204-211.

Tong A, Sainsbury P, Craig J (2007). Consolidated criteria for reporting qualitative research (COREQ): a 32-item checklist for interviews and focus groups. International Joural for Quality in Health Care, 19(6), 349-357.

Trusson D, Rowley E, \& Bramley L (2019). A mixed-methods study of challenges and benefits of clinical academic careers for nurses, midwives and allied health professionals. BMJ Open, 9, 
Newington L, Alexander CM, Wells M. What is a clinical academic? Journal of Clinical Nursing 2020

e030595.

van Oostveen CJ, Goedhart NS, Francke AL, \& Vermeulen H (2017). Combining clinical practice and academic work in nursing: A qualitative study about perceived importance, facilitators and barriers regarding clinical academic careers for nurses in university hospitals. Journal of Clinical Nursing, 26(23-24), 4973-4984.

Wenke R, \& Mickan S (2016). The role and impact of research positions within health care settings in allied health: A systematic review. BMC Health Services Research, 16, 355.

World Health Organization (2019). Gender equity in the health workforce: Analysis of 104 countries. Health Workforce Working Paper 1. Available at:

https://www.who.int/hrh/resources/gender_equity-health_workforce_analysis/en/ (accessed 18 October 2020).

Tables

Table 1. Participant demographics

\begin{tabular}{|c|c|c|}
\hline \multicolumn{3}{|c|}{ Research-active clinicians ( $n=12$ ) } \\
\hline $\begin{array}{l}\text { Clinical } \\
\text { discipline }\end{array}$ & $\begin{array}{l}\text { Nursing } \\
\text { Midwifery } \\
\text { Speech and language therapy } \\
\text { Occupational therapy } \\
\text { Radiography } \\
\text { Dietetics } \\
\text { Pharmacy }\end{array}$ & $\begin{array}{l}4 \\
2 \\
2 \\
1 \\
1 \\
1 \\
1\end{array}$ \\
\hline $\begin{array}{l}\text { Academic } \\
\text { level }\end{array}$ & $\begin{array}{l}\text { Pre-doctoral } \\
\text { Doctoral } \\
\text { Post-doctoral }\end{array}$ & $\begin{array}{l}5 \\
3 \\
4\end{array}$ \\
\hline Hospital site & $\begin{array}{l}\text { A } \\
B \\
C \\
D\end{array}$ & $\begin{array}{l}3 \\
2 \\
4 \\
3\end{array}$ \\
\hline Funding body & $\begin{array}{l}\text { National Institute for Healthcare research } \\
\text { NIHR Imperial Biomedical Research Centre / Imperial Health Charity } \\
\text { Other }\end{array}$ & $\begin{array}{l}4 \\
5 \\
3\end{array}$ \\
\hline $\begin{array}{l}\text { Year of clinical } \\
\text { qualification }\end{array}$ & $\begin{array}{l}\text { Median } \\
\text { Range }\end{array}$ & $\begin{array}{l}2004 \\
1984-2016\end{array}$ \\
\hline Gender & $\begin{array}{l}\text { Female } \\
\text { Male }\end{array}$ & $\begin{array}{ll}10 \\
2\end{array}$ \\
\hline \multicolumn{3}{|c|}{ Clinical managers $(n=8)$} \\
\hline Clinical area† & $\begin{array}{l}\text { Nursing/midwifery } \\
\text { Allied health professions } \\
\text { Other non-medical professions }\end{array}$ & $\begin{array}{l}3 \\
3 \\
2\end{array}$ \\
\hline Gender & $\begin{array}{l}\text { Female } \\
\text { Male }\end{array}$ & $\begin{array}{l}7 \\
1\end{array}$ \\
\hline
\end{tabular}

† Specific allied health and other non-medical professions are not listed separately to preserve participant anonymity. 
Figure legends

Figure 1. Thematic representation of 'what is a clinical academic'

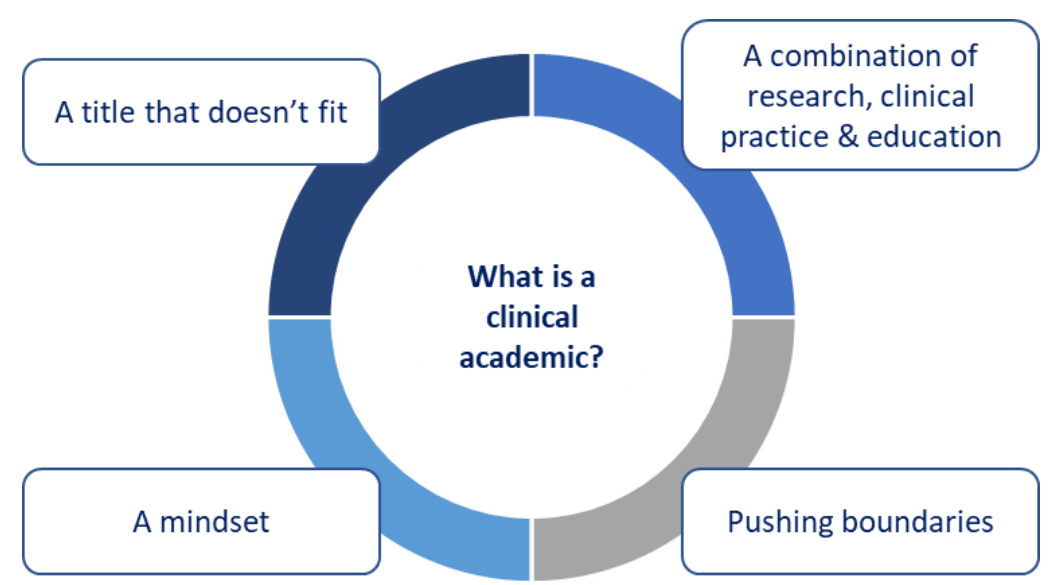

